\title{
PROTEÇÃO DA PROPRIEDADE INTELECTUAL: \\ IMPLICAÇÃO ECONÔMICA NO CENTRO DAS PREOCUPAÇÕES DOS PAÍSES \\ DA AMÉRICA LATINA
}

Héloïse Vanderaa

\section{RESUMO}

Os países latino-americanos que ratificaram as mais importantes convenções internacionais em matéria de proteção da propriedade intelectual encontram dificuldades na transposição dessas normas para as legislações nacionais e, quando há transposição, a aplicação apresenta problemas.

Palavras-chave: propriedade intelectual ; convenções internacionais; países latinoamericanos

Protection of the intellectual property: economical implication in the center of the concerns in Latin America countries

\begin{abstract}
The Latin-American countries that ratified the most important international conventions of the intellectual property rigths have difficulties in the transposition of those norms for their national legislations and, when there is transposition, the application presents problems.
\end{abstract}

Keywords: intellectual property; international conventions; Latin-American countries 


\section{Introdução}

A dificuldade de transposição e de aplicação efetiva das normas de direito internacional na área da propriedade intelectual penalizam os países em desenvolvimento não somente na atração de investidores mas também nas negociações dos acordos de livre comércio com os outros países ditos desenvolvidos, cujas exigências de proteção não podem ser atendidas nesta matéria e, particularmente, em matéria de luta contra a falsificação. Pressionados pelos países industrializados, os países da América Latina uniram-se no combate contra a pirataria, uma das exigências fundamentais em termos de proteção da propriedade intelectual para o desenvolvimento dos investimentos empresariais. De acordo com a vontade dos países industrializados de fortalecer a proteção da propriedade intelectual no plano internacional, os países em desenvolvimento, na primeira fila, o Brasil, consideram que essa proteção deva ser orientada no sentido de favorecer seu desenvolvimento.

\section{Conformidade quase completa com relação às convenções internacionais}

Os países latino-americanos assinaram as principais convenções internacionais em matéria de propriedade intelectual, principalmente os acordos da OMC (ADPIC), de $1^{\circ}$ de janeiro de 1995, sobre os aspectos do direito de propriedade intelectual que dizem respeito ao comércio. A obrigação de estar em conformidade com as legislações internas está mais ou menos completa segundo os países (em 1995, para a Argentina ; em 1996, para o Brasil).

No Chile, a transposição dos acordos ADPIC atrasou com relação ao que estava previsto. Inicialmente, não politicamente prioritário, em seguida, sujeito ao lobbying por parte de alguns setores industriais (sobretudo, o setor farmacêutico, pois não existe patente específica para os produtos farmacêuticos, e o setor de produtos de luxo, que reivindica o reconhecimento do estatuto notório de marca), o projeto de lei ficou sob análise em instâncias legislativas durante mais de quatro anos, após a data prevista de implantação. Por fim, as modificações que deveriam ser feitas na lei de propriedade intelectual $\mathrm{n}^{0} 19.039$ foram aprovadas pelo Parlamento e pelo Senado no final de novembro de 2004.

Apesar das promessas, a Bolívia está em atraso na transposição dos ADPIC, sendo necessário constatar a fraca vontade de fortalecer seu sistema de proteção da propriedade intelectual. O projeto de lei de fevereiro de 2001, que permitia alinhar a legislação boliviana aos ADPIC, não foi ainda analisado pelo Congresso. 


\section{Implantação freqüentemente difícil dos direitos de propriedade intelectual}

Mesmo quando transpõem para as suas legislações internas as normas internacionais em matéria de propriedade intelectual, os países da América Latina têm dificuldades em aplicá-las e oferecem proteção considerada "teórica" do problema, no que diz respeito à luta contra a falsificação. Em toda a região, a falsificação, principalmente das marcas de luxo, desenvolve-se de modo considerável.

\section{a) Implantação difícil dos mecanismos de luta contra a falsificação}

$\mathrm{Na}$ Argentina e no Brasil, as novas legislações não possibilitaram revogar os numerosos problemas de falsificação nem proteger as patentes dos laboratórios farmacêuticos. A Argentina assinou os acordos de Marrakech de $1995^{1}$, que estão em vigor desde aquela data, em aplicação do artigo $75 \S 22$ da Constituição de 1994, que dá aos tratados internacionais valor superior ao das leis. Entretanto, a aplicação das novas medidas legislativas em matéria de propriedade intelectual apresenta problemas no país, principalmente no âmbito do dispositivo institucional de luta contra a falsificação, ainda frágil. Os investidores (em especial, as empresas do setor de bens de consumo de luxo) constatam o grande número de falsificações que circulam no território argentino, sobretudo por meio dos pequenos comércios da cidade de Buenos Aires e das províncias do nordeste do país. Na Argentina, a falsificação representaria um prejuízo de 3 bilhões de USD por ano para a sociedade. Dos produtos falsificados, $60 \%$ seriam fabricados no próprio território. A falsificação abrange, geralmente, todas as marcas de produtos e bens de consumo, inclusive produtos farmacêuticos.

Quanto ao Brasil, os acordos ADPIC foram transpostos para a legislação nacional em 1996. Enquanto os textos correspondem aos critérios internacionais, o Brasil sofre de má aplicação dos dispositivos e das sanções existentes, tornando a proteção efetiva da propriedade intelectual muito frágil. Ameaçado, nos últimos tempos, por sanções econômicas norte-americanas e pressionado pelos países desenvolvidos, o Brasil tenta dar prova de mais rigor diante dos graves problemas de defesa dos direitos de propriedade intelectual em seu próprio território, sobretudo em termos de pirataria.

Uma das principais preocupações dos investidores estrangeiros no Brasil diz respeito à pirataria. O que é importante evidenciar é a falsificação não abranger somente o setor de bens de consumo de luxo mas também todos os setores, principalmente a indústria fonográfica, o

\footnotetext{
${ }^{1}$ Lei 24.425 - Buletim Oficial de 5 de janeiro de 1995.
} 
setor de audiovisual, a indústria farmacêutica, de softwares, cigarros, brinquedos e peças automotivas. Confira o quadro 1 abaixo.

\section{Quadro 1 : A pirataria no Brasil, números sobre os principais setores afetados anualmente \\ (Fonte : Brazil - U.S. Council)}

\begin{tabular}{|l|}
\hline Audiovisual \\
$30 \%$ das vendas provêm da pirataria. \\
17.000 postos de trabalho deixam de ser criados por causa da pirataria. \\
120 milhões de USD de prejuízo em vendas não faturadas. \\
\hline Indústria fonográfica \\
$52 \%$ das vendas provêm da pirataria. \\
55.000 postos de trabalho deixam de ser criados por causa da pirataria. \\
82 milhões de USD de prejuízo em impostos não recolhidos. \\
\hline Softwares \\
$61 \%$ das vendas provêm da pirataria. \\
785 milhões de USD de prejuízo em vendas não faturadas. \\
\hline Softwares profissionais \\
$55 \%$ das aplicações provêm da pirataria. \\
187 milhões de USD de prejuízo em vendas não faturadas. \\
\hline Indústria de cigarros \\
$34 \%$ das vendas provêm da pirataria. \\
51 bilhões de cigarros vendidos ilegalmente. \\
500 milhões de USD de prejuízo em impostos não recolhidos. \\
\hline Indústria de brinquedos \\
$12 \%$ das vendas provêm da pirataria. \\
80.000 postos de trabalho deixam de ser criados por causa da pirataria. \\
31 milhões de USD de prejuízo em vendas não faturadas. \\
\hline Outros setores \\
$48 \%$ das vendas de óculos escuros provêm da pirataria. \\
$10 \%$ das vendas de peças automotivas provêm da pirataria. \\
$5 \%$ a $7 \%$ da venda de todos os produtos médicos provêm da pirataria. \\
\hline
\end{tabular}

Um dos setores mais atingidos pela falsificação no Brasil é o da indústria fonográfica. Os CDs piratas circulam nas ruas de maneira maciça ${ }^{2}$. Algumas associações do setor, principalmente a Sociedade Brasileira de Administração e de Proteção dos Direitos Intelectuais (SOCINPRO), propõem soluções ao governo federal, como o aumento do preço da matéria-prima utilizada para a reprodução de obras intelectuais, os CDs e fitas cassetes virgens. Porém, antes de mais nada, uma operação de sensibilização da população, organizada conjuntamente pelos setores público e privado, parece indispensável.

\footnotetext{
${ }^{2}$ Cf. Quadro 2.
} 


Quadro 2 : Indústria fonográfica no Brasil : conseqüências da pir
\[ \begin{array}{l}\text { (Fonte : ADPIF e ABPD) } \\ \text { - Queda de 67\% nas vendas de CDs inéditos (de } 1997 \text { a } \\ \text { - } 1 \text { em cada } 2 \text { CDs vendido no Brasil é pirata. } \\ \text { - } 270 \text { milhões de USD movimentados pela pirataria de CDs. } \\ \text { - As vendas de CD caíram 25\% em 2003. } \\ \text { - Fechamento de } 2 \text { milhões de pontos de venda de CDs. } \\ \text { - Queda de 7\% nos lançamentos de novos CDs. } \\ \text { - O índice de pirataria de CDs passou de 3\% para 59\% de } \\ 1997 \text { a } 2002 . \\ \text { - Apreensão de } 17 \text { milhões de CDs piratas em } 2003 .\end{array} \]

No Chile, onde o mecanismo de apreensão previsto na lei em vigor é difícil de executar, a pirataria nas áreas literária e artística aumentou significativamente em 2002; da mesma forma que na Bolívia e no Peru, apesar dos esforços de repressão das autoridades peruanas e da falta de recursos. Na Bolívia, a pirataria dos direitos autorais, na maioria dos setores industriais, encontra-se entre as mais altas do mundo. No Uruguai, ainda que exista mobilização crescente em prol da luta contra a pirataria para posicionar o país como plataforma logística na região, a organização do combate à pirataria é ainda pouco eficiente. $\mathrm{Na}$ Colômbia, embora o novo código penal preveja penas consideráveis para os crimes ligados à propriedade intelectual e à falsificação e apesar das campanhas de sensibilização das autoridades públicas, a aplicação do código esbarra na obstrução das jurisdições penais. Confira o quadro 3 abaixo.

\section{Quadro 3 : A pirataria nos outros países da América Latina}

(Fonte : Rede das Missões Econômicas francesas na América Latina)

\section{Chile}

- $35 \%$ das vendas de vídeo-cassates.

- $51 \%$ dos softwares.

- $40 \%$ das vendas de discos.

Argentina

- A indústria da falsificação gera 6 bilhões de USD.

- $60 \%$ dos produtos falsificados são oriundos de uma indústria local, o resto é importado, particularmente dos países asiáticos.

Peru

98\% das vendas de discos.

\section{Bolívia}

Desde 1988 o índice de pirataria em matéria de direitos autorais varia entre $77 \%$ e $88 \%$. 
Os países latino-americanos, conscientes do problema, defendem-se, sobretudo diante da Organização Mundial da Propriedade Intelectual - OMPI, por uma constatação: um país em desenvolvimento não pode praticar as mesmas medidas de proteção que um país desenvolvido.

\section{b) Por iniciativa do Brasil, os países do Mercosul uniram-se na luta contra a pirataria}

Diante da dimensão do fenômeno e pressionado pelos EUA, o governo brasileiro implantou, em maio de 2003, uma Comissão Parlamentar de Inquérito (CPI) com a missão de questionar a luta contra a pirataria, no sentido amplo do termo. A criação de uma CPI é prevista pelo regulamento interno da Câmara dos Deputados e precisa ter a aceitação de, no mínimo, um terço dos deputados. Com caráter temporário, tem como objetivo investigar um tema preciso de interesse público e as ordens constitucional, legal, econômica ou social do país. A CPI dispõe dos mesmos poderes de investigação das autoridades jurídicas.

A CPI da Pirataria entregou, em agosto de 2004, o relatório no qual propunha a implantação do "Plano Nacional de Luta contra a Pirataria", assim como a criação de um organismo público encarregado de formular e coordenar políticas públicas na luta contra a pirataria: o Conselho Nacional de Luta contra a Pirataria e os Crimes contra a Propriedade Intelectual, criado em $1^{\mathrm{o}}$ de outubro de $2004^{3}$. Este Conselho, cuja tutela é do Ministério da Justiça, reúne representantes dos poderes Executivo, Legislativo e das indústrias fonográfica, audiovisual, de softwares e do livro. Reuniu-se pela primeira vez, em Brasília, no dia 14 de janeiro de 2005, para definir seu funcionamento. A segunda reunião, nos dias 27 e 28 de fevereiro de 2005, definiu e implantou a estratégia de combate à pirataria, compreendendo noventa e nove medidas de ação. O Conselho dispõe de dois anos para colocar em prática suas ações, de acordo com três eixos principais: sensibilização, repressão e implicações econômicas; as operações conjuntas das polícias e da Receita Federal serão sua principal arma. Além de propor meios de luta contra a pirataria, a fraude fiscal e os crimes contra a propriedade intelectual, o Conselho auxiliará o poder Legislativo na definição dos projetos de ação, de investigação, de prevenção e de repressão, mas desenvolverá, também, campanhas de sensibilização da população. Está prevista a realização de estudos em colaboração com o setor industrial que dizem respeito à possibilidade de redução dos preços das mercadorias.

\footnotetext{
${ }^{3}$ Medida Provisória no 220 de 1\%10/2004; Decreto nº 5.244 de 14/10/2004.
} 
$\mathrm{Na}$ ótica de concretização da vontade política, a Polícia Federal brasileira fortaleceu suas ações nessa área. Desde o início do ano, as apreensões de produtos falsificados provenientes principalmente da Ciudad de Leste, no Paraguai, representam mais de 850.712 USD: 395.335 USD de apreensões em ônibus - a metade deste total corresponde a cigarros e o restante, de produtos eletrônicos, informática, pneus, CDs e DVDs virgens. O total de veículos apreendidos chega a 155.000 USD. À guisa de ilustração, desde o início de 2005 :

- 50 toneladas de rolamentos automotivos falsificados foram apreendidos na cidade de Pimenta Bueno (RO);

- 4 depósitos de óculos falsificados foram fechados no Rio de Janeiro;

- 1 ônibus com 390 caixas de cigarros (195.000 pacotes) e com materiais de informática foi apreendido em Foz do Iguaçu;

- $\quad 400$ caixas de cigarros e 2.700 vidros de perfume foram apreendidos em Foz do Iguaçu.

Nessa perspectiva e com a iniciativa do Brasil, que tem demonstrado vontade firme de lutar contra a falsificação, os países do Mercosul, a Bolívia, o Chile e o Peru adotaram, durante a reunião dos ministros de Justiça e de Relações Exteriores do Mercosul em Brasília em 25 de novembro de 2004, um acordo de cooperação na luta contra a pirataria, o contrabando de cigarros e de qualquer outro produto. $\mathrm{O}$ texto tem caráter operacional e não precisará de aprovação legislativa nacional.

Esse acordo, destinado a implantar ações conjuntas complementares à ação dos mecanismos nacionais, prevê a realização direta de ações nos ministérios competentes, com meios definidos e validados semestralmente pelos ministérios. O objetivo geral do acordo é programar operações conjuntas dos órgãos de fiscalização dos países signatários, de modo simultâneo e coordenado, particularmente nas fronteiras, no sentido de reprimir a pirataria e o contrabando, em especial de cigarros.

Os países signatários comprometem-se a:

- $\quad$ verificar a existência de empresas envolvidas nesses crimes e a veracidade dos dados;

- identificar os responsáveis ;

- fiscalizar o abastecimento dos produtos desde a origem até a distribuição ;

- fiscalizar e controlar os estoques dos produtos ;

- comparar os dados sobre importações e exportações.

De acordo com o diagnóstico da situação de cada país, serão empreendidas ações coordenadas pelos serviços de informação respectivos, graças ao intercâmbio de informações nas seguintes áreas : 
- dados estatísticos sobre as pessoas envolvidas nos crimes e o número de detidos;

- instrumentos utilizados, mercadorias e somas movimentadas;

- $\quad$ tipos de crimes;

- $\quad$ número de investigações e de processos;

- $\quad$ fábricas e distribuidores ilegais de cigarros ou de outro produto.

Todo pedido de investigação deverá depender do Protocolo de Assistência Jurídica Mútua para Questões Penais do Mercosul ou de outro instrumento de cooperação jurídica internacional em questões penais, em vigor entre os países signatários do acordo. A programação das ações comuns poderá ser desenvolvida paralelamente às ações policiais e de fiscalização dos órgãos nacionais competentes em cada país.

No que diz respeito ao contrabando de cigarros, serão adotados dispositivos, como o uso de etiquetas, selos, carimbos ou outro elemento de controle, que serão do conhecimento de todos os países participantes, graças a um banco de dados específico. Serão também registradas e trocadas informações sobre o tráfico aduaneiro de cigarros, o volume de cigarros produzidos, importados e exportados, a origem e o destino, assim como os dados sobre o consumo interno.

Com essa iniciativa regional, as autoridades brasileiras querem mostrar a determinação em atacar o problema da pirataria e tentam certificar-se da eficácia da luta contra a falsificação. O Paraguai será objeto de atenção especial por ser o país de origem da maioria das mercadorias falsificadas da região.

\section{Propriedade intelectual, um dado inerente dos acordos de livre comércio}

Durante as negociações dos acordos de livre comércio, os países da América Latina, especialmente o Brasil, recusam qualquer comprometimento que vá além dos já acordados no âmbito dos ADPIC, ou acordos concluídos anteriormente pelos EUA. Em razão da difícil implantação dos dispositivos internacionais, o tema da propriedade intelectual faz parte dos assuntos centrais e controvertidos dos acordos de livre comércio em discussão entre países da América Latina e países desenvolvidos. Este tema foi também um dos maiores pontos de conflito nas negociações, atualmente bloqueadas, da Área de Livre Comércio das Américas. 


\section{a) Implicação nas negociações dos acordos de livre comércio entre a UE e o Mercosul}

Entre a União Européia e o Mercosul, o pedido europeu de abandono do uso de indicações geográficas usurpadas constituiu obstáculo para as negociações. Essa questão também deu origem a intensas negociações que precederam a conclusão do acordo de associação entre a UE e o Chile. A usurpação de marcas originais na Argentina, principalmente francesas e italianas (vinhos e queijos), constitui litígio recorrente nas relações bilaterais, traduzindo-se em concorrência comercial desleal que deturpa a notoriedade de produtos agro-alimentares.

\section{b) Implicação nos acordos de livre comércio entre os EUA e os países da América Latina}

A luta contra a pirataria está no centro das atuais preocupações norte-americanas e representa o surgimento de uma série de bloqueios nas negociações comerciais bilaterais entre os países latino-americanos e os EUA. Os norte-americanos lançaram um programa de ação governamental destinado à proteção dos direitos de propriedade intelectual: a Estratégia contra a Pirataria Organizada (dita STOP). Nesse sentido, os norte-americanos ameaçam, com represálias, os países que não fariam, segundo eles, esforços suficientes para combater a falsificação.

Os EUA ameaçam o Brasil há mais de um ano com a perda de benefício do Sistema Geral de Preferências (SGP), que permite exportar para o mercado norte-americano em condições tarifárias preferenciais, conduzindo as autoridades brasileiras a fortalecer, de maneira considerável, a luta contra a falsificação. A decisão de tirar o Brasil do SGP deveria ter sido tomada pelo governo dos EUA em setembro de 2004; insatisfeitos com as medidas adotadas pelo Brasil na questão, os norte-americanos, em primeiro momento, adiaram a decisão para o final de março de 2005 e anunciaram novo adiamento para setembro de 2005 . Atualmente, 14\% dos produtos brasileiros exportados para os EUA fazem parte do SGP, ou seja, o equivalente a 2,5 bilhões de USD.

A Bolívia, admitida em 2002 no programa norte-americano ATPDEA (Andrean Trade Program and Grug Eradication), que chega ao seu fim, deu provas, segundo os EUA, de certo laxismo na luta contra a pirataria, vendo-se relegada à posição de observador, enquanto os outros países da Comunidade Andina de Nações (CAN) já iniciaram negociações com vistas a um acordo de livre comércio. O tratado de livre comércio entre o Chile e os EUA, em vigor 
desde $1^{\circ}$ de fevereiro de 2004, contém disposições fortes contra a pirataria, a cópia de patentes farmacêuticas e as competências das alfândegas em matéria de apreensão. O Peru negocia, em conjunto com a Colômbia e o Equador, um acordo de livre comércio com os EUA, que poderia obrigá-lo a rever a legislação atual (da CAN) sobre os organismos vivos que podem ser patenteados e estender a duração das patentes para mais de vinte anos.

\section{Reivindicação da propriedade intelectual a serviço do desenvolvimento}

Sempre em conformidade com os convênios internacionais, os países latinoamericanos desejam ampliar o sistema internacional de proteção da propriedade intelectual. $\mathrm{O}$ Brasil apresentou, em 28 de setembro de 2004, conjuntamente com a Argentina e com o apoio de vários países (Bolívia, Cuba, Equador, Irã, Quênia e Venezuela), uma proposta à OMPI de modificação do modo de ação da Organização, acusada de favorecer indevidamente os detentores de patentes e os países desenvolvidos. Aos olhos do Brasil, o nível de desenvolvimento do país deveria ser levado em conta quando se tratar de exigir a proteção da propriedade intelectual, sabendo-se que um país em desenvolvimento não poderá adotar as mesmas medidas de proteção que um país desenvolvido.

Lembrando que o desenvolvimento continua a ser uma das implicações mais urgentes para a comunidade internacional, que se mobilizou por várias vezes (sobretudo por meio dos Objetivos do Milênio, do Consenso de Monterrey e da Agenda de Doha), esse grupo de países em desenvolvimento propõe :

- Adotar medidas a fim de que, em todos os países, os custos da proteção não prevaleçam sobre as vantagens. Segundo a constatação de que as promessas de progresso científíco não diminuíram a fratura entre países ricos e países pobres, o Brasil estima que tanto a proteção quanto a harmonização das legislações referentes à propriedade intelectual não poderiam ser consideradas como um fim em si.

- No âmbito da adoção de normas discutidas atualmente na OMPI (projeto sobre o tratado de direito material das patentes), preservar as cláusulas de interesse público e as flexibilidades previstas nas legislações nacionais de muitos países em desenvolvimento.

- No que diz respeito à transferência de tecnologia, levar em conta que os países em desenvolvimento que aceitaram obrigações mais penosas em matéria de propriedade intelectual carecem de infra-estrutura e de capacidade institucional para absorver essa tecnologia, pois o fortalecimento das normas de proteção da propriedade intelectual não permite estimular a transferência de tecnologia pelo investimento estrangeiro direto e pela 
concessão de licenças. Em conseqüência, foi sugerida a criação de novo órgão subsidiário na OMPI encarregado de analisar as medidas a serem adotadas no âmbito do sistema de propriedade intelectual, a fim de garantir a transferência de tecnologia efetiva em proveito dos países em desenvolvimento.

- Que a aplicação dos direitos de propriedade intelectual deva ser considerada no contexto maior do interesse social e do desenvolvimento, preservando o direito dos países de respeitar suas obrigações internacionais no âmbito de seus próprios sistemas e práticas jurídicas, os procedimentos de aplicação dos direitos devendo ser justos e eqüitativos.

- Que os programas de cooperação técnica que têm como objeto as questões de propriedade intelectual devam ser ampliados e melhorados a fim de que os custos de proteção da propriedade intelectual não ultrapassem as vantagens decorrentes.

Os EUA reagiram vigorosamente a esta proposta, declarando que não viam como a frágil proteção dos direitos de propriedade intelectual poderia aumentar a competitividade e fomentar maior desenvolvimento tecnológico. 